\title{
Simulation of Scenarios and Urban Analysis Using Parametric Modeling and Genetic Algorithm Based on Multicriteria Analysis
}

\author{
Silvio Romero Fonseca Motta \\ PUC-MG / Brazil \\ silvio.motta@gmail.com
}

\author{
Ana Clara Moura Mourão \\ UFMG / Brazil \\ anaclara@ufmg.br
}

Ana Clara Zandonaidi Galvão
PUC-MG / Brazil
anazandonaidi@gmail.com

\author{
Suellen Roquete Ribeiro \\ UFMG / Brazil \\ suellenribeiro@yahoo.com \\ Julia Marion Florencio Kato \\ UFMG / Brazil \\ marionkato1@gmail.com
}

\begin{abstract}
The present paper surveys a method of changing the adequacy level of variables in multicriteria analysis (MCA) using parametric modeling. The aim is to simulate if-then scenarios to support resilience designs. The case study is a MCA for Pampulha region, Belo Horizonte, Brazil. The parametric model was developed in Grasshopper software, and defines, by knowledge-driven, a set of weight for an increased environmental quality which generates an index of suitability for each territorial unit. The if-then simulation changes the level of adequacy of 3 variables using a genetic algorithm, which calculates new distribution patterns for the MCA adequacy level.
\end{abstract}

Keywords: Multicriteria analysis; Parametric modeling; Genetic algorithm; Urban analysis; Scenario simulation.

\section{Introduction}

The urban context is composed of several variables which are in constant interaction and transformation. Creating a synthesis of urban analysis implies combining and associating several data. Nowadays, most of the information has a spatial component; so that, we can consider it as geographic data. In this sense, the decision making process in urban planning directly involves the analysis of geographic data, mostly in a synthesized way. One example of urban synthesized analysis is the composition of a Multicriteria Analysis (MCA) which can be a methodology for multiple urban studies. Basically, it combines different variables in order to compose a summarized integrated model to support a decision making process.

Specifying the variables, or layers, that compose the MCA means to set a decision context according to the objective of study. Likewise, scoring the variables means to indicate their level of adequacy also according to the objective. This may be established in accordance with the current and existing situation or be composed according to future expectation, or future scenarios. To simulate different future scenarios we can change the score or level of adequacy of the variables.

In this context, in this paper it is investigated methods of changing the adequacy level of variables in a MCA through parametric modeling. The goal is to simulate future scenarios, which explore adaptable and flexible solutions, using a genetic algorithm (GA) that alters the level of adequacy of each variable to find new patterns of synthesis results. The final scenario is expected to present an environmental quality based on the principle of equality. The equality in environmental quality can be an important strategy for resilience solution in urban scale. This equality is achieved through balancing the potentials in the area, seeking for the smallest difference between the final synthesis result, which indicate the variable's index of suitability; that is, the best possible way to equilibrate the conditions within the area. The simulation scenario based on the principle of equality is an important support for adaptable solution and resilience design.

\section{Methods}

The methodology adopted in the research was the Design Science (DSR). The research sought for a solution to a real problem. The solution was based on theoretical foundations and aimed to respond to the real case as much as to be adaptable to other cases. The research was development in 6 steps, as shown by table 1 .

Table 1: Steps of research development.

\begin{tabular}{|l|l|}
\hline $\begin{array}{l}\text { 1.Find a relevant practical } \\
\text { problem: }\end{array}$ & $\begin{array}{l}\text { Alterations in the indexes of } \\
\text { suitability of the MCA variables }\end{array}$ \\
\hline $\begin{array}{l}\text { 2.Examine the research } \\
\text { potential: }\end{array}$ & $\begin{array}{l}\text { Literature review of MCA and } \\
\text { GA }\end{array}$ \\
\hline $\begin{array}{l}\text { 3. Obtain theoretical and } \\
\text { practical knowledge: }\end{array}$ & $\begin{array}{l}\text { Searching for MCA and GA } \\
\text { tools }\end{array}$ \\
\hline 4. Solution proposal: & $\begin{array}{l}\text { Development of a genetic } \\
\text { parametric model in } \\
\text { Grasshopper (McNeel, 2013) }\end{array}$ \\
\hline $\begin{array}{l}\text { 5. Implement and test the } \\
\text { solution: }\end{array}$ & $\begin{array}{l}\text { Simulate scenarios in } \\
\text { Pampulha }\end{array}$ \\
\hline 6. Ponder the applicability: & Evaluate the results \\
\hline
\end{tabular}


Firstly, to define the theoretical basis, the article presents a literature review about MCA and GA concepts. After presenting the investigation of the theoretical knowledge, the parametric model that was developed using Grasshopper software is described. In order to test the model, genetic simulations of future scenarios were performed using the Pampulha Region, Brazil, as a study area. Finally, the article presents a critical analysis of the observed results.

\section{Literature Review \\ Multicriteria Analysis}

The Multicriteria Analysis (MCA) is a decision-making method for complex planning problems involving multiple criteria. The method is based on mathematical operation to establish a synthesis of the combined criteria. The results of this combination are based in the relative importance of each criterion. The relative importance is defined by people involved in the process using several methods and techniques (Dodgson, 2009).

MCA can be used as a methodology of urban study, which combines and associates geographic data of different variables in order to support a decision-making (Jankowski \& Richard, 1994). In an MCA urban study, a level of adequacy of each variable is defined or scored for each geographic unit (lot, block or neighborhood), according to its adequacy to the objective of analysis.

One of the most common procedures in MCA is the weighted linear combination method. According to Eastman et al. (1995), in this method, a weight is multiplied by each variable's level of adequacy and then summed with its value for other variables to get a final index of suitability for each unit. Thus, a suitability map results from the combination of weighted variables. In order to increase the reliability of the process, there are several methodologies for the definition of weights. Bonham-Carter (1994) defines the process of data-driven evaluation, when the data guide the level of importance of the variable, and knowledge-driven evaluation, when weights are listed by experts' opinions. The extensive amount of methods for the definition of weights contrasts with those for the scores definitions. In general, the scores need to be standardized for the same measurement unit, in order to be combined (Eastman et al., 1995).

The decision set for an MCA will vary according the objective of investigation. Thus, it is important to highlight the direct connection between the results and the set of variables. Essentially, the results fit in a specific context in time and space, and each new analysis will require new choices of variables and weights (Moura, 2007). Specifying the scenario in which the analysis takes place involves the definition of measurable variables. It is important to emphasize the summarizing aspect of the MCA, in the sense that the goal is to produce a model, and as a model, it simplifies the real complexity representing the reality through different variables (Moura, 2009).

The methodology adopted involves the application of an MCA based on the weighted linear combination method, with a knowledge-driven evaluation process. In the context of a Multicriteria Analysis, the set of variables usually indicates the existing conditions. The paper proposes simulations if-then, where the methodological model operates hypothetical scenarios of if the context changes, then the index of suitability becomes more balanced. The simulations, considered as possible future scenarios or contexts, can be made through the modification of the condition of each variable. Therefore, the model operates a variation on the scores among the territorial units on the search for new patterns that are in accordance to the objective.

\section{Parametric modeling and genetic algorithm}

Parametric modeling is largely used in architecture nowadays to generate new shapes in contemporary projects. It adopts parameters and functions by computing process that explores the potential of geometric modeling (Florio, 2011). Parameters and functions are connected and organized through algorithms to be altered and manipulated in a logic process. In most cases, it creatively explores the mathematical possibilities in architectural scale but it is also slightly used in urban scale. In urban planning there are a few groups using parametricism, such as Zaha Hadid Architects (Schumacher, 2009). Nevertheless, the referred modeling is not so applied in cartography and spatial visualization mechanisms. Instead, it is only used by those who exploit the PPGIS (Planning Participatory GIS) possibilities as a future landscape production mechanism (Leach, 2009); and in simulation of parameters alterations for production of dynamic cartography by Parametric Modeling in Territorial Occupation (PMTO) (Moura, 2012).

Parametric modeling allows the use of evolutionary computing based on algorithms (genetic algorithms) that embrace Darwinian principles to calculate process (Simon, 2013). The genetic algorithm uses trial and error approach in order to solve a function or a group of functions to numerical optimization (Bäck, Fogel \& Michalewicz, 1997). The optimization of a function aims to find the best result to a problem solving. This is called a fitness function. In fact, this solution is not necessarily exact or determinist, but a heuristic solution for the issue (Michalewicz \& Fogel, 2013). This approach is suitable in solutions of inaccurate or even impossible problems phenomena. Those problems often have meta-heuristics characteristics and the calculation of the numerical optimization solution gives a group of heuristic possible results, in other words, a group of approximated results to the problem resolution's criterion. New populations of individuals/results are generated for potential evolution in the problem solving. The decision of the following events to be calculated for the future populations works in an undefined way. Once the best available value is defined by the repeated populations, the adequate solution for the problem is concluded.

The Darwinian principles are used for the development of the populations' results and to determine the behavior of the calculation. The genetic algorithms ascertain, by evolutionary principles, how the parameters are going to interact and how the calculations development will generate, select, evaluate and choose the population of results (Hingston, Barone \& Michalewicz, 2008).

Simulation using evolutionary computing has an analysis potential for inaccurate problems. These problems must have 
a consistent structure with this heuristic nature. It usually uses storage methods in order to develop the calculations. The calculation evolution or even the several attempts to search an adequate solution to the problem works in a random way. The main purpose is to calculate a population of potential results/individuals to reach the best available solution. The results from the generated population are confronted with the desired solution and identified its level of suitability towards the problem solving. News generations of populations are subsequently calculated from the previous generation to find a more possible suitable solution.

\section{Results and Analysis \\ Multicriteria Analysis tool using Genetic Algorithm}

The Multicriteria Analysis tool consists in a parametric model developed in Grasshopper software using genetic algorithms. The parametric model algorithm considers the following steps (Figure 1).

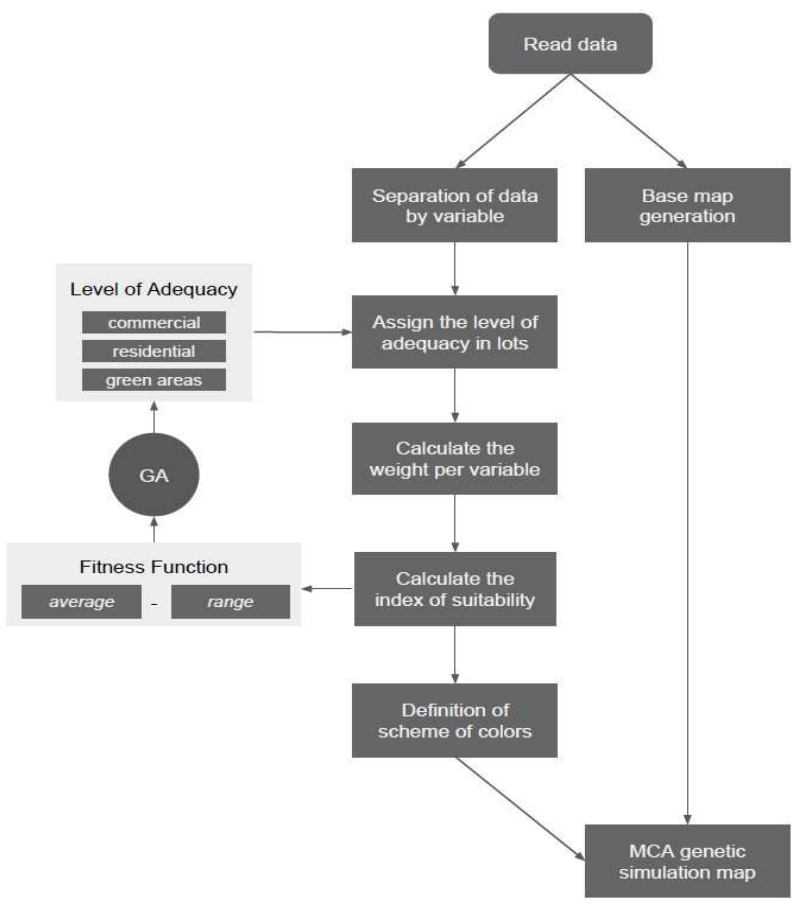

Figure 1: Flowchart of Grasshopper algorithm steps

The Figure 2 below shows the algorithm such as viewed in Grasshopper's interface:

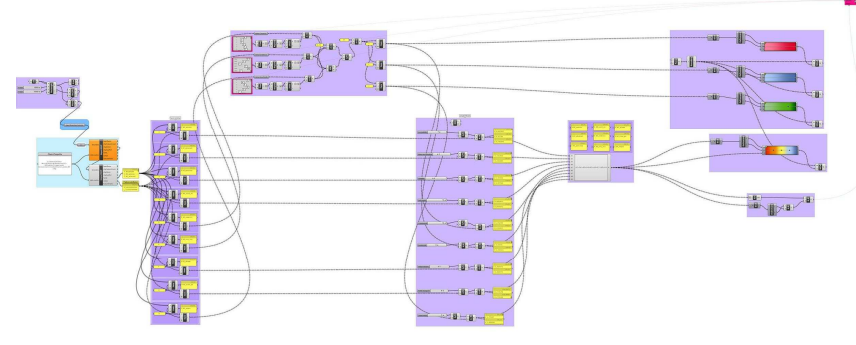

Figure 2: Grasshopper's interface with the algorithm
Firstly, the parametric model processes a database by importing a shapefile $(s h p)$ that was made with nine variables (accessibility, water and flooding, visibility, built index, commercial use, residential use, urban dynamic, public transport and green areas). The shp was previously prepared using ArcGis, with spatial reference in UTM WGS-84 coordinate system. The imported shp composed the georeferenced database in Rhinoceros/Grasshopper (McNeel, 2013), as shown in the figure below (Figure 3).

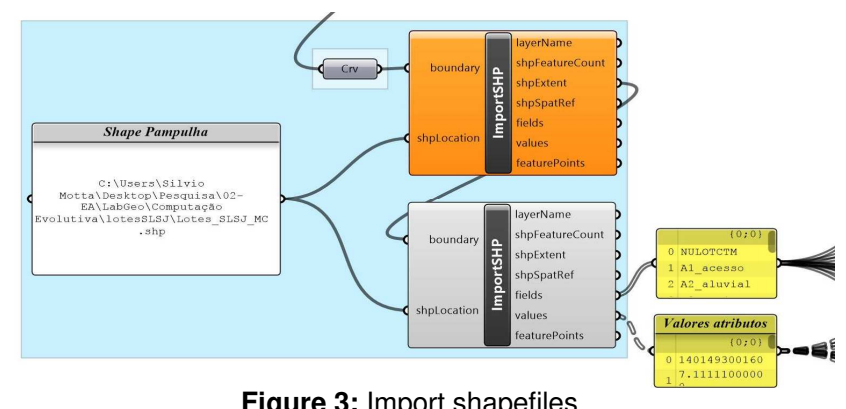

After that, the algorithm separates the level of adequacy of the nine variables individually and associates them one by one in each geo-referenced lot (Figure 4).

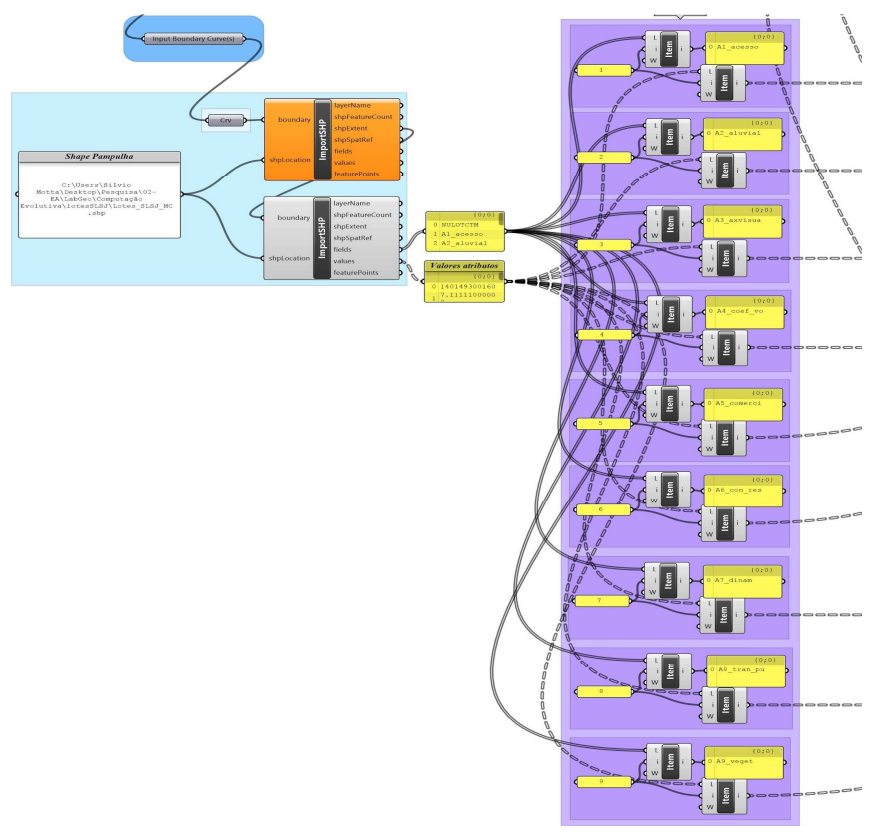

Figure 4: Separation of the variables by the algorithm

- Using the levels of adequacy of the geo-referenced lots, the algorithm process the MCA calculations. The tool allows the simulation of different sets of weights, in order to generate distinct scenarios. In this way, a mathematical calculation strategy was used to define the set of weight. In an MCA, the set of weight must have a sum of $100 \%$. This means that the weight value of one variable reflects on the others. In the tool, each variable has the weight defined by a value in a range of 0 to 10 and the algorithm calculate the relative percentage of this value considering the value defined in other variables. This strategy was called Dynamic Calculation of MCA weights (Figure 5). 


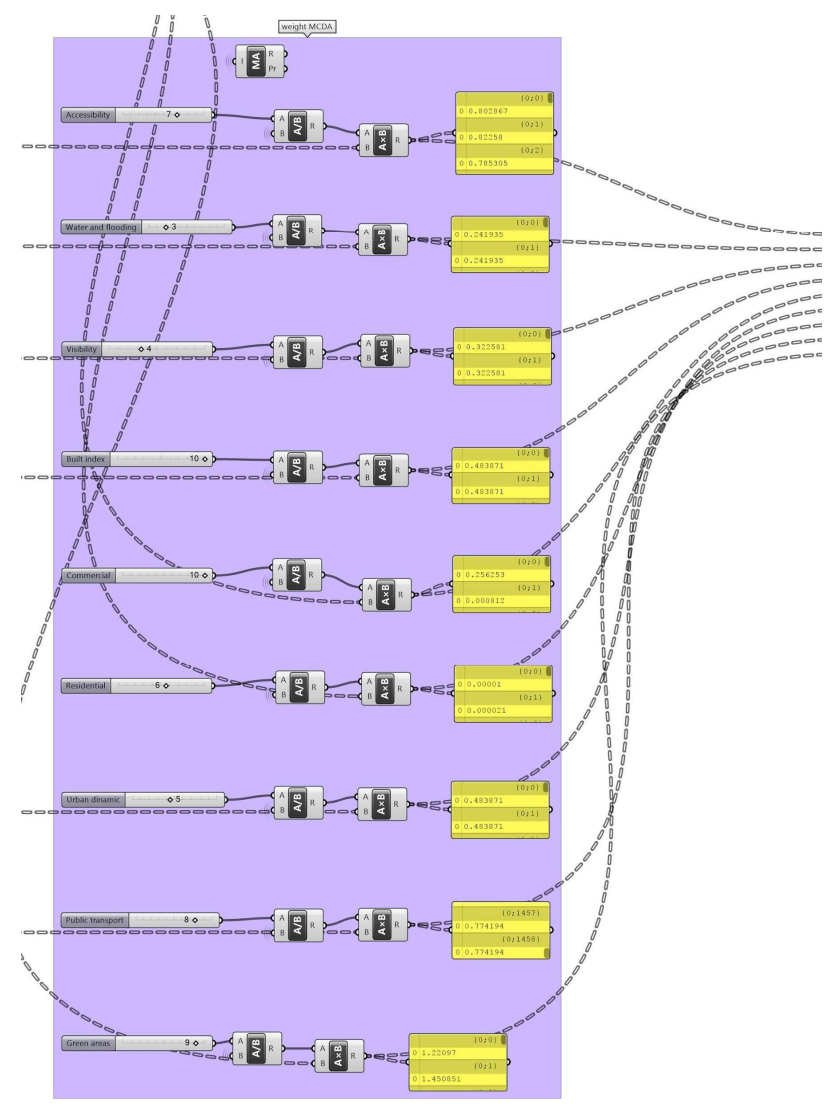

Figure 5: Dynamic calculation of MCA weights

Subsequently, the next part of the algorithm composed the modification of the conditions of each variable to simulate future scenarios. The simulation of possible scenarios and contexts can be done varying the scores/level of adequacy. Considering that if/then simulations of new territorial patterns imply alteration of land use, the research chooses the three main land use variable to perform the variation of the units' scores. The variables chosen were: residential, commercial and green variables. They were modeled considering the portion of the lot's area that would be occupied by each of those uses.

A genetic algorithm strategy was applied in residential, commercial and green areas variables. It uses the Galapagos function, which is part of Grasshopper tools, to simulate different levels of adequacy, used as gens in calculation of new distribution patterns of the index of suitability in the area. For this, these three variables pass through the genetic algorithm (Figure 6 ) before going to the dynamic calculation of weights.

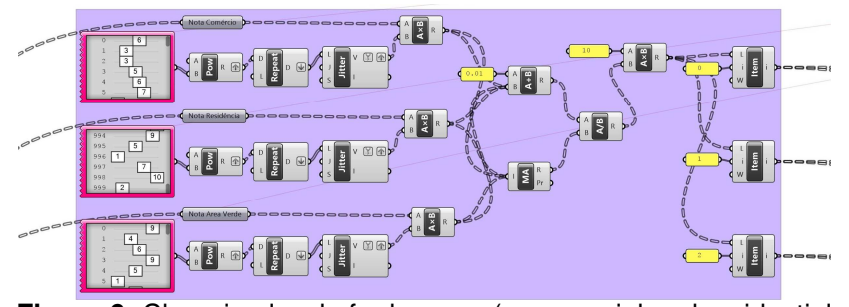

Figure 6: Changing level of adequacy (commercial and residential use and green areas)
Parallel to the dynamic calculation of the index of suitability, the algorithm models a map of the area from the georeferenced points. The shp file prepared for this research used the region of Pampulha, Belo Horizonte, Minas Gerais. The territorial unit adopted was the urban lot. A 2D basemap of the area was generated to be used as a map view of the different aspect like, variables (one by one), synthesis of results, etc. (Figure 7).

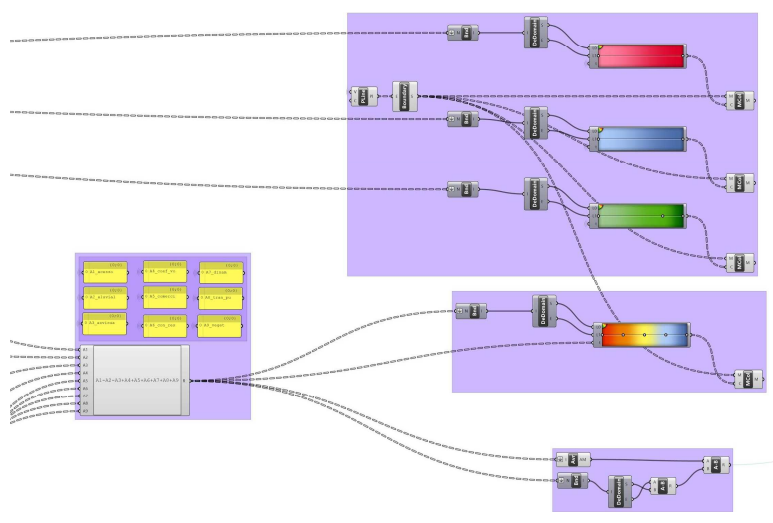

Figure 7: Creating the map view

Afterwards, the results of the index of suitability dynamic calculation were associated to the map of the territorial units through a color scheme. For the visualization, a different scheme was adopted for each variable that was altered by the genetic algorithm. The residential variable was drawn using red gradient. The commercial variable used a blue gradient. The green areas variable used a green gradient. In these cases, stronger colors indicate higher values. For the final MCA map (index of suitability), a red to blue gradient was adopted, where red indicates low values, yellow indicates mean values and blue indicates high values.

\section{Experiment of genetic simulation}

In order to simulate scenarios in Pampulha, it was made an experiment of MCA using the genetic algorithm. Firstly, a set of weights were defined and put in Grasshopper. This definition was made by academic expert. The objective pursued was to generate an index of suitability for each territorial unit in a way to increase the environmental quality. The set of variables and their weights may vary according to the goal of the research. In this case, the set was composed by 9 variables with the weights as shown by table 2 . In order to develop the study, the definition of the variables, as much as their set of weights, were defined by academic specialists for an exemplification. Although the method of definition for the set of variables is not the focus of research, it is important to highlight that this process of definition faces a classic question for which various researchers proposes some methods. Some of the possible processes of definition are discussed by Moura et al. (2016). The Table 2 shows the variables and their respective weights to the MCA. 
Table 2: Set of weight

\begin{tabular}{|l|l|}
\hline Accessibility & 7 \\
\hline Water and Flooding & 3 \\
\hline Visibility & 4 \\
\hline Built index & 10 \\
\hline Commercial & 10 \\
\hline Residential & 6 \\
\hline Urban dynamic & 5 \\
\hline Public transport & 8 \\
\hline Green areas & 9 \\
\hline
\end{tabular}

Subsequently, the genetic algorithm changes the level of adequacy of commercial, residential and green areas variables. For this alteration, we adopted a strategy that the sum of the three variables must be 10 . In that way, any alteration in one variable implies on altering the others.

The variation was based on a mathematical equation that multiplies by a factor the previous values of the level of adequacy of each lot in each variable. The factor used for the multiplication was modeled as a slider, with values from 1 to 10. The values of this slider are the genes of genetic calculation. The gen pool command was used to create a set of the sliders, one for each lot, to get a different variation of the factor to be used for each lot. In addition, the algorithm predicts an exponential increase in factor value before multiplying it with the previous level of adequacy. This was adopted in order to obtain great variations in the changes.

$$
\begin{gathered}
\text { Final level }_{i}=\frac{\text { initial level }_{i} \times \text { factor }^{2}}{\left.\sum_{i}^{n} \text { (initial level }_{i} \times \text { factor }^{2}\right)} \times 10 \\
i=1 \text { e } n=3
\end{gathered}
$$

The fitness function considered two aspects of the index of suitability results when the genetic calculation changes the levels of adequacy. The first was the average of the values in all area. The second was the range of all values (difference between maximum and minimum value). The objective of the fitness function was to find the highest values of average combined with lower values of range. For it, the equation of fitness function was defined as:

$$
\rightarrow \quad(\text { average })-(\text { range) }
$$

The genetic simulation was performed using an evolutionary solution method. It was generated 121 generations with 50 populations of the 1459 individuals/lots each. A great increase in fitness score was observed until the 10th generation. Between the 10th and the 18th generation, the result had a medium increase and after the 18th generation, it showed very small increases. Figure 8 shows the window during the genetic simulation.

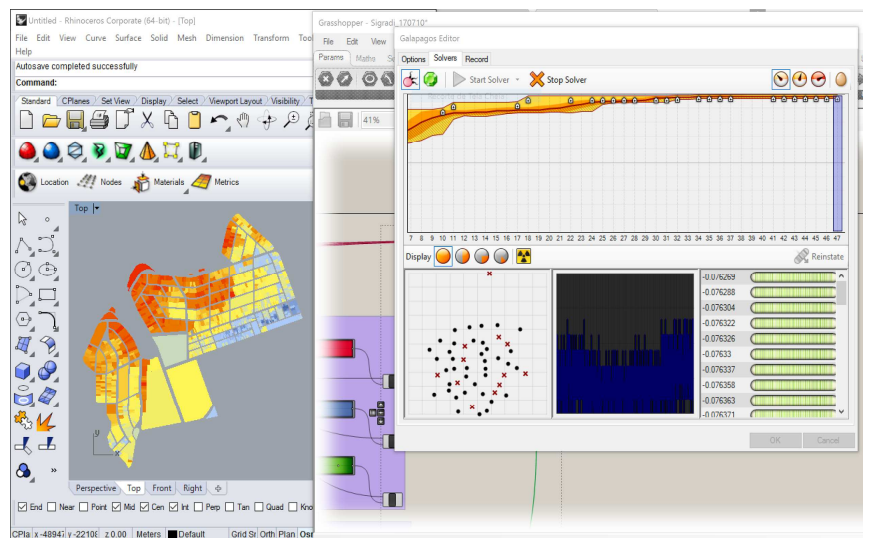

Figure 8: Genetic simulation

The Figure 9 shows the maps of each variable considering the initial value of level of adequacy. The Figure 10 shows the results obtained in the level of adequacy after the genetic calculation.

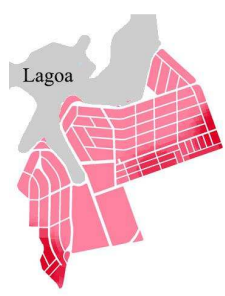

a. Level of adequacy. Variable: resitential

Figure 9: Initial level of adequacy

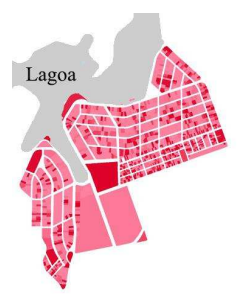

a. Level of adequacy. Variable: resitential

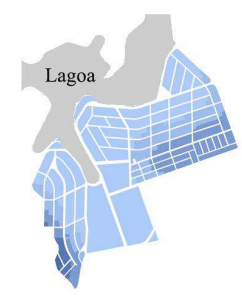

b. Level of adequacy.

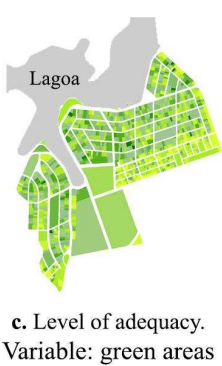

Figure 10: Level of adequacy after genetic simulation

It is possible to observe some aspects when analyzing the initial level of adequacy maps and the results. Firstly, in the map of residential variable (Figure 9a), the strongest scores, represented by the darker color, are concentrated in a particular area, exclusively. In other words, according to this map, the occurrence of residential use is concentrated in two areas, both of them located in the south. In addition, Figure $9 b$, which shows the commercial variable, indicates that this use occurs in specific regions located in the south. It also indicates, that the area has grown in way that concentrates the residential and commercial use in similar places, occasionally in the same territorial unit. On the other hand, Figure 9c shows no concentration intended for green areas. For this case, the lots with stronger colors are interspersed and heterogeneous all over the map.

In the maps of level of adequacy after simulation (Figure 10), 
it is verified that the highest incidence of each use had great changes after the genetic calculation. For example, Figure $10 \mathrm{a}$, which represents the residential variable, shows high scores in various points, including the region closest to Pampulha Lake, where there were no high levels before. The same occurs with the commercial variable (Figure 10b), showing a scenario with high scores in different areas, intercalating with residential and green areas. Finally, in the green areas, shown by Figure 10c, the high scores are presented in different lots, even in a heterogeneous way.

The genetic simulated experiment indicated that, when we have the use associate with the three variables distributed heterogeneously in the area, the final results have high average and low range, according with the initial hypothesis of environmental quality based on the principle of equality for strategy of resilience solutions on the urban scale. The final result of the MCA genetic experiment in index of suitability, compared to the initial situation, is shown in figure 11.
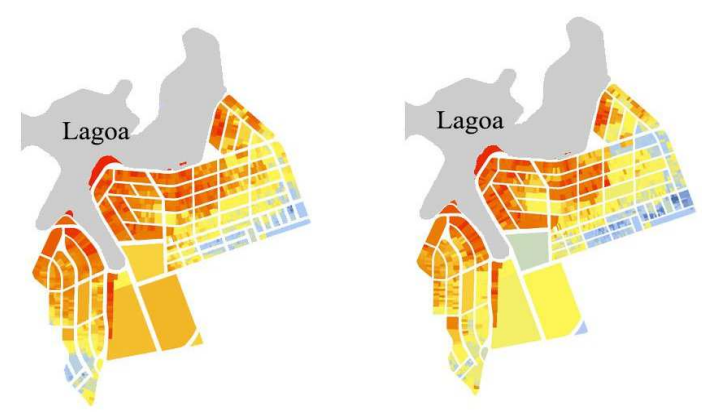

a. Initial index of suitability. b. Final index of suitability.

Figure 11: Comparison between indexes of suitability maps

\section{Discussion and Conclusions}

The MCA is a traditional and useful method to support the urban planning process. The use of MCA for simulation if-then has a great potential and the challenges to this are the methods of changing parameters and calculation methods. Changes in level of adequacy have potential as a good strategy for simulation if-then using MCA. Knowing that these changes are often a complex calculation, the use of genetic algorithm proved adequate as a methodology approach. The research evaluated a Grasshopper algorithm modeled to be the engine of the simulation of different levels of adequacy in an MCA. The experiment proved to be adequate for calculating the simulation if-then. The main issue was the definition of the objective of the simulation and the definition of the fitness function according to it. In the experiment, the objective was an environmental quality, defined by specialists through the set of weight. The environmental quality was not very clear during the experiment and this proved to be important for an accurate definition of the fitness function and the results of the simulation if-then using genetic methods. As the objective of this research was to evaluate the applicability of genetic algorithm in simulation if-then, the experiment was sufficient and this use was shown as a great potential. The results maps of the genetic simulation have great diversity when compared with the initial maps. Further explorations may be undertaken to investigate possible consequences of the solutions suggested by the observed results.

\section{Acknowledgements}

We acknowledge the support of CNPq - National Council for the Scientific and Technological Development, through the PIBIC 2016/2017 scholarship. We also would like to thank FAPEMIG for the support in the project number FIP 2017/432S1.

\section{References}

Jankowski, P., and Richard, L. (1994). Integration of GIS-Based Suitability Analysis and Multicriteria Evaluation in a Spatial Decision Support System for Site Selection, Environment and Planning B, 21(6):323-340.

Eastman, J. R.; Jin, W.; Kyem, P.A.K.; Toledano, J. (1995) Raster procedures for multicriteria/ multi-objective decisions. Photogrammetric Engineering and Remote

Sensing, v.61, n.5, p. 539-547.

Bäck, T., Fogel, D. B., \& Michalewicz, Z. (1997). Handbook of evolutionary computation. Release, 97(1), B1.

Moura, A. C. M.. (2007). Reflexões Metodológicas como subsídio para estudos ambientais baseados em Análise de Multicritérios. Anais XIII Simpósio Brasileiro de Sensoriamento Remoto, Florianópolis, Brazil, 2007, INPE, p. 2899-2906.

Hingston, P. F., Barone, L. C., \& Michalewicz, Z. (Eds.). (2008). Design by evolution: advances in evolutionary design. Springer Science \& Business Media.

Dodgson, J. S., Spackman, M., Pearman, A., \& Phillips, L. D. (2009) Multi-criteria analysis: a manual.

Moura, A. C. M.. (2009). Discussões metodológicas para aplicação do modelo de Polígonos de Voronoi em estudos de áreas de influência fenômenos em ocupações urbanas - estudo de caso em Ouro Preto - MG. Anais VII Encontro Nacional da Associação Brasileira de Estudos Regionais e Urbanos - ENABER, São Paulo, Brasil, 9-11, FEA/USP.

Schumacher, P. (2009). Parametricism: A new global style for architecture and urban design. Architectural Design, 79(4), 14-23.

Leach, N. (2009) Special Issue: Digital Cities. Architectural Design, 79(4) $135 \mathrm{p}$

Florio, W. (2011). Modelagem paramétrica, criatividade e projeto: duas experiências com estudantes de arquitetura. Gestão e Tecnologia de Projetos, v. 6, n. 2, 2011. p. 43-66.

Moura, A. C. M.. (2012). Learning topics in urban planning at UFMG: geoprocessing to support analysis, planning and proposal of the urban landscape at neighborhood scale. Paranoá, v. 7, p. 51-59.

McNeel, R. (2013). Grasshopper 3D [computer software].

McNeel, R. (2013). Rhinoceros 3D v5 [computer software].

Michalewicz, Z., \& Fogel, D. B. (2013). How to solve it: modern heuristics. Springer Science \& Business Media.

Simon, D. (2013). Evolutionary optimization algorithms. John Wiley \& Sons

Moura, A. M., Ribeiro, S. R., Guadalupe, D. C., \& Motta, S. R. (2016). Visualisation Tools in Grasshopper+Rhino3D to Improve MultiCriteria Analysis in Urban Policies - Case Study of Pampulha, Brazil. 9th International Conference on Innovation in Urban and Regional Planning. 1, pp. 404-410. Torino: Istituto Superiore Sui Sistemi Territoriali per L'innovazione (SiTI) 